\title{
Comportamento verbal: um contraponto pericial acerca da prova testemunhal e seu valor no âmbito jurídico penal/criminal
}

\section{Verbal behavior: an expert counterpoint regarding testimony and its value in the criminal legal framework/criminal}

\author{
Leonardo Mendes Cardoso ${ }^{1}$, Lorismário Ernesto Simonassi ${ }^{2}$
}

Cardoso LMC, Simonassi LE Comportamento verbal: um contraponto pericial acerca da prova testemunhal e seu valor no âmbito jurídico penal/criminal. Saúde, Ética \& Justiça. 2015;20(2):66-76.

RESUMO: Este artigo trata das questões do valor da prova testemunhal sob o foco da análise do comportamento verbal em correspondência com os comportamentos verbal e não verbal, na busca de elementos suficientes para sua validação ou não no plano jurídico penal/criminal. O objetivo da pesquisa é procurar entender se existem tais elementos e que valor probatório lhes poderia ser atribuído do ponto de vista prático nas audiências e nos tribunais de júri, uma vez que as provas médico-periciais nem sempre atendem adequadamente a esta necessidade. Assim, o encontro de tais subsídios jurídicos tenderia a minimizar os erros porventura cometidos nestas esferas da Justiça, o que, por si só, já reflete a relevância do tema. Para tanto, nos valemos de uma análise qualitativa, com base em pesquisas literárias, dissertativas, descritivas e exploratórias. Nossos principais referenciais teóricos foram o Código de Processo Penal e, no plano autoral, Skinner. Ao final, alcançamos a conclusão de que, por tratar-se de comportamento verbal sujeito à influência de variáveis diversas, não identificáveis e cujos controladores não são facilmente perceptíveis, a prova testemunhal não possui nenhuma base de concretude que lhe possa impor confiabilidade, exceto quando outras variáveis - a exemplo de contradições e/ou de provas materiais concretas - sejam encontradas.

DESCRITORES: Prova pericial; Comportamento verbal; Direito penal; Criminologia.

${ }^{1}$. Doutorando em Análise Comportamental - Psicologia / PUC Goiás, Brasil.

2. Doutor em Psicologia. Professor orientador. Doutorado em Análise Comportamental - Psicologia / PUC Goiás, Brasil. Endereço para correspondência: Leonardo Mendes Cardoso. Avenida Tocantins, n. 1121. Apart. 901 Setor Aeroporto, GoiâniaGo, CEP 74.075-100. 


\section{INTRODUÇ̃̃O}

área penal/criminal do Direito
depende, em muitos momentos, da
prova testemunhal para a elucidação de fatos ilícitos cometidos, sobretudo contra a vida e/ ou o patrimônio. Por se tratar de uma prova baseada apenas no relato verbal dos fatos - e que nem sempre podem ser devidamente comprovados por meio de contradições e/ou de provas concretas acerca do que foi verbalizado - acabará por se constituir num elemento probatório subjetivo, frágil, sujeito a variáveis diversas, desconhecidas e incontroláveis. O problema na prática é não saber sob o controle de quem ou do quê estará tal comportamento verbal vocal.

A Medicina Legal, por meio da análise dos vestígios encontrados nos locais dos fatos, nem sempre consegue alcançar a materialidade direta como prova suficiente para o julgamento das lides. Assim, a prova testemunhal, segundo os ditames legais, "poderá" suprirlhe a falta.

Partindo destas informações preliminares, o tema a ser abordado em nosso artigo é a prova testemunhal, com delimitação no seu valor a partir das análises do comportamento verbal em correspondência ou não com outros comportamentos verbais e não verbais que possam ser identificados quando dos relatos das testemunhas. Trata-se da tentativa de encontro de dados verificáveis e/ ou de sinais confiáveis e mensuráveis que possam surgir como consequência da emissão de tais comportamentos pelas testemunhas.

Para nortear o trabalho a que nos propusemos, o problema da pesquisa foi o seguinte: Existem indicativos consistentes, clinicamente verificáveis e juridicamente aceitáveis de que uma testemunha mente ou diz a verdade por meio da análise de seu comportamento verbal em correspondência com outros comportamentos - verbais ou não verbais - por ela emitidos durante seus relatos?

A nossa proposta é a de que o comportamento verbal, sendo comportamento operante, encontra-se sob o controle de inúmeras variáveis, as quais são, por sua vez, desconhecidas em grande parte das vezes, e por isto não é possível identificar seus estímulos controladores, seja numa audiência ou num tribunal de júri. Assim sendo, a prova testemunhal só deverá merecer valor probatório naqueles casos específicos em que as contradições são flagrantes, principalmente quando provas materiais concretas forem alcançáveis pelas diversas perícias, entre elas as médico-legais.

A relevância do tema se justifica a partir do momento em que condenações ou absolvições contrárias à verdade dos fatos ocorrerem. Os custos social e financeiro de tais erros jurídicos são enormes e, por vezes, irreparáveis. Vejamos um exemplo, publicado no jornal eletrônico Hoje em Dia ${ }^{1}$ :

STJ dará a palavra final sobre um dos maiores erros

\section{jurídicos em MG}

Está nas mãos da ministra do Superior Tribunal de Justiça (STJ), Eliana Calmon, a decisão sobre um episódio que pode ter sido um dos erros jurídicos que mais causaram danos a um inocente em Minas. Wagno Lúcio da Silva, de 46 anos, um quebrador de pedras e segurança de boate em Congonhas, na região central mineira, ficou preso injustamente durante quase nove anos por um crime que não cometeu. Quando deixou a prisão, cheio de cicatrizes e sem dentes de tanto apanhar, Wagno era apenas um esboço de si mesmo. $\mathrm{O}$ advogado criminalista Dino Miraglia se interessou pelo caso e ingressou com ação na Justiça contra o Estado e requereu uma indenização por perdas e danos morais no valor de R 7 milhões.

Além do mais, interesses diversos podem ser estímulos controladores da emissão de falsos testemunhos e, mesmo que erros judiciais venham a ser corrigidos num futuro, os danos causados permanecem como máculas indeléveis. Basta vermos o que ocorre com aqueles que são condenados por crime de estupro mesmo que inocentes sejam - e que, no interior das celas são brutalmente violentados como forma de punição a partir do emprego de ditames morais e éticos por parte de outros detentos cujas morais também deixaram a desejar em algum momento de suas vidas. Para nossas pesquisas nos valeremos de uma abordagem qualitativa, por meio de revisão literária, dissertativa, descritiva e exploratória.

Assim, acreditamos que os médicos peritos devam ser treinados quanto à análise do comportamento verbal, uma vez que podem basear suas análises nos relatos emitidos pelas alegadas vítimas, por agressores ou mesmo pelas testemunhas dos fatos. Para nossas pesquisas, nossos principais referenciais teóricos serão o Código de Processo Penal ${ }^{2}$ - CPP -, e Skinner ${ }^{3}$.

\section{COMPORTAMENTO VERBAL E PROVA TESTEMUNHAL}

No mundo jurídico penal, a prova pericial do crime é a base para o julgamento de um processo e, em diversas ocasiões, sem ou mesmo com tais provas materiais concretas angariadas e validadas por meio de ações periciais, o testemunho de alguém pode assumir relevante valor probatório, por vezes mudando rumos e alterando sentenças. Assim sendo, necessária se faz a análise consistente do valor da prova testemunhal para que equívocos não sejam cometidos ou, pelo menos, para que ocorram de forma minimizada. Para tanto, os caminhos exigem o confrontamento entre o comportamento verbal vocal-depoimento ou testemunho-e as correspondências deste com os demais comportamentos - verbal ou não verbal - na intenção de que tal estratégia de abordagem possa revelar se a testemunha está a relatar ou não a 
"verdade dos fatos". E isto se deve em parte à ineficácia da prova médico-legal em alguns casos, a exemplo das denunciações caluniosas de estupro. Na sequência tentaremos elucidar aquilo que advogamos como sendo a verificação necessária para a validação ou invalidação da prova testemunhal como elemento processual, sobretudo nos valendo de uma análise médico-pericial dos sinais não verbais - taquicardia, tremores, alteração da pressão arterial etc., e seus valores como meios de prova.

\section{Acerca da prova testemunhal no âmbito jurídico penal/criminal}

Iniciamos julgando ser imprescindível o esclarecimento acerca do significado da prova testemunhal no âmbito jurídico penal/criminal. Para tanto, vale dizer que ela é ordenada por nosso Código de Processo Penal ${ }^{2}$, estando lá verificada nos seguintes artigos:

\section{LIVRO I \\ DO PROCESSO EM GERAL \\ TÍTULO II \\ DO INQUÉRITO POLICIAL}

Art. $5^{\circ} \S 1^{\circ}$ alínea "c": a nomeação das testemunhas, com indicação de sua profissão e residência. [...]

\section{TÍTULO VII \\ DA PROVA \\ CAPÍTULO II \\ DO EXAME DO CORPO DE DELITO, E DAS PERÍCIAS EM GERAL}

Art. 167: Não sendo possível o exame de corpo de delito, por haverem desaparecido os vestígios, a prova testemunhal poderá suprir-lhe a falta. [...]

Art. $168 \S 3^{\circ}$ : A falta de exame complementar poderá ser suprida pela prova testemunhal.

\section{CAPÍTULO VI \\ DAS TESTEMUNHAS}

Art. 202. Toda pessoa poderá ser testemunha.

Art. 203. A testemunha fará, sob palavra de honra, a promessa de dizer a verdade do que souber e lhe for perguntado, devendo declarar seu nome, sua idade, seu estado e sua residência, sua profissão, lugar onde exerce sua atividade, se é parente, e em que grau, de alguma das partes, ou quais suas relações com qualquer delas, e relatar o que souber, explicando sempre as razões de sua ciência ou as circunstâncias pelas quais possa avaliar-se de sua credibilidade.

Art. 204. O depoimento será prestado oralmente, não sendo permitido à testemunha trazê-lo por escrito.

Parágrafo único. Não será vedada à testemunha, entretanto, breve consulta a apontamentos. [...]

Art. 206. A testemunha não poderá eximir-se da obrigação de depor. Poderão, entretanto, recusar-se a fazê-lo o ascendente ou descendente, o afim em linha reta, o cônjuge, ainda que desquitado, o irmão e o pai, a mãe, ou o filho adotivo do acusado, salvo quando não for possível, por outro modo, obter-se ou integrar-se a prova do fato e de suas circunstâncias. [...]

Art. 208. Não se deferirá o compromisso a que alude o art. 203 aos doentes e deficientes mentais e aos menores de 14 (quatorze) anos, nem às pessoas a que se refere o art. 206. [...]

Art. 210. As testemunhas serão inquiridas cada uma de per si, de modo que umas não saibam nem ouçam os depoimentos das outras, devendo o juiz adverti-las das penas cominadas ao falso testemunho. (Redação dada pela Lei ${ }^{\circ} 11.690$, de 2008)

Parágrafo único. Antes do início da audiência e durante a sua realização, serão reservados espaços separados para a garantia da incomunicabilidade das testemunhas. (Incluído pela Lei $\mathrm{n}^{\circ} 11.690$, de 2008)

Art. 211. Se o juiz, ao pronunciar sentença final, reconhecer que alguma testemunha fez afirmação falsa, calou ou negou a verdade, remeterá cópia do depoimento à autoridade policial para a instauração de inquérito. [...]

Art. 212. As perguntas serão formuladas pelas partes diretamente à testemunha, não admitindo o juiz aquelas que puderem induzir a resposta, não tiverem relação com a causa ou importarem na repetição de outra já respondida. (Redação dada pela Lei $n^{\circ} 11.690$, de 2008) [...]

Art. 213. O juiz não permitirá que a testemunha manifeste suas apreciações pessoais, salvo quando inseparáveis da narrativa do fato. [...]

Art. 215. Na redação do depoimento, o juiz deverá cingir-se, tanto quanto possível, às expressões usadas pelas testemunhas, reproduzindo fielmente as suas frases. [...]

Art. 217. Se o juiz verificar que a presença do réu poderá causar humilhação, temor, ou sério constrangimento à testemunha ou ao ofendido, de modo que prejudique a verdade do depoimento, fará a inquirição por videoconferência e, somente na impossibilidade dessa forma, determinará a retirada do réu, prosseguindo na inquirição, com a presença do seu defensor. (Redação dada pela Lei $\mathrm{n}^{\circ} 11.690$, de 2008) [...]

Em primeiro lugar, vale ressaltar que os artigos acima expostos trazem explicitadas determinações pertinentes a comportamentos verbais e formas de controle aversivo para os quais não se tem a noção de como tal controle será procedido. Notamos, pois, que a prova testemunhal é um recurso jurídico possível, mas que terá valor relativo no devido processo legal. Ainda mais, se faz ordenada por dispositivo que objetiva afirmar seu valor, quando buscada no curso das fases de instrução e julgamento, com a finalidade de que colabore, como juridicamente esperado, para o encontro da "verdade dos fatos" e não como fonte de implantação de dúvidas ou entraves. Neste sentido a prova testemunhal, e mesmo sob um olhar inicial que indaga tal expectativa jurídica anteriormente citada, para os operadores do Direito 
tem sido considerada, de longas datas, como sendo "a prostituta das provas", dada a sua fragilidade, uma vez que está sujeita a impressões pessoais e contingências diversas (cf. Art. 213 CPP). ${ }^{2}$

Segundo determina o Art. $158 \mathrm{CPP}^{2}$ : "quando a infração deixar vestígios será indispensável o exame de corpo de delito, direto ou indireto, não o suprindo a confissão do acusado".

Portanto, entende-se que a prova testemunhal é um recurso a mais a ser utilizado quando as provas concretas da materialidade dos fatos não puderem ser alcançadas por meio de atos periciais, diretos ou indiretos.

Segundo Rangel, citado por Santos ${ }^{4}$,

[...] o objeto da prova é a coisa, o fato, o acontecimento que deve ser conhecido pelo juiz, a fim de que possa emitir um juízo de valor. São os fatos sobre os quais versa a lide. Ou seja, é o thema probandum que serve de base à imputação penal feita pelo Ministério Público. É a verdade dos fatos imputados ao réu com todas as suas circunstâncias. (p. 406)

E é a busca dessa "verdade" que norteia as ações penais/criminais com o fito de que equívocos judiciais não sejam cometidos ou, pelo menos, que sejam cometidos em menor grau. Não se trataria de não errar, mas de errar menos. Neste sentido, os réus - sujeitos da acusação de algum fato delituoso - contam com as garantias constitucionais e a nossa Carta Magna de $1988^{5}$ prevê a ampla liberdade de defesa, o caráter paritário de posição das partes, o direito ao contraditório e a livre apresentação das provas pelas partes envolvidas na lide.

A prova testemunhal se faz valer, ainda, pelo princípio da oralidade, remetendo-nos à interpretação de que o comportamento verbal, por meio da fala, será o foco central da análise de juízes, de promotores, de advogados, de defensores públicos e/ou do corpo de jurados. Porém, vale frisar que todos estes elementos humanos acham-se eivados de impressões próprias e que, por certo, influirão no juízo de valores emitidos por eles. Também os níveis culturais e as formações morais variarão de indivíduo para indivíduo, sobretudo se levarmos em conta os repertórios dirigentes de seus pensamentos, racionalizações e condutas.

Continuando, tanto as testemunhas quanto aqueles demais componentes do processo judicial estarão sujeitos a impressões que nem sempre corresponderão com a tal "verdade" perseguida para a consecução da justiça. Interesses diversos permearão os comportamentos verbais orais das testemunhas, tanto quanto as possíveis interpretações das falas por parte daqueles que decidem de que lado se encontra a tal "verdade dos fatos".

Os ditames do $\mathrm{CPP}^{2}$ em relação à prestação de depoimentos testemunhais preveem sanções com o objetivo precípuo de inibição das falsidades relativas ao que se irá declarar. Isso, por si só, já é fator intimidador e, mesmo que se considere estar dizendo a "verdade", tal momento expressará uma natural tensão implicando em fator estressante capaz de redundar em alterações orgânicas e/ou psíquicas - sudorese, tremores, boca seca, lapsos de memória, gagueira, mãos frias etc. - que podem interferir na interpretação dos ouvintes, impondo menor credibilidade aos fatos narrados e podendo atuar como mecanismos controladores daquilo que será verbalizado, segundo dados da Ordem dos Advogados de Portugal, citado por Campina. ${ }^{6}$

Porém, há que se perguntar se tais sanções são capazes de inibir a emissão de falsas respostas ou se teremos o comportamento verbal vocal do falante sob o controle tão somente da audiência e não pelas possíveis punições a que a lei o sujeita ou mesmo por inúmeros outros estímulos controladores não identificados. Uma inter-relação entre tais variáveis também poderia estar envolvida e, assim, deveria ser averiguada como possibilidade fática. No decorrer da pesquisa esperou-se obter maiores esclarecimentos neste sentido.

De extrema importância seria que a testemunha se limitasse ao relato do fenômeno, mas não é isso o que geralmente ocorre, prevalecendo em boa parte dos casos a sobreposição de suas impressões próprias, dirigidas por suas percepções e emoções e principalmente pelo controle da audiência e da interação entre variáveis que ocorrem no discurso verbal. ${ }^{7,8}$ Daí ser considerado temeroso o julgamento de crimes de repercussão midiática ainda no "calor dos ânimos". Nas palavras de Bottomore e Nisbet": “[...] o homem não age simplesmente sob o efeito de um estímulo mecânico, mas porque quer alguma coisa por certas razões. Tem motivos" (p. 228). Seria o mesmo que dizermos que fatos são os fenômenos contaminados por diversas variáveis e que suas interpretações se acham na dependência de tais interesses pessoais, ou seja, motivadores.

Conforme ensinamentos de Weber, citado por Weschler ${ }^{10}$, teríamos as ações individuais do sujeito norteadas por um amplo conjunto de variáveis. Seriam elas, segundo o que se pode depreender de sua leitura, as ações motivadas pela razão e voltadas para o cumprimento e o alcance de um determinado objetivo; as ações de igual cunho racional e relacionadas a um determinado valor moral; as ações afetivo-emocionais, indicadas pela expressão emocional e comportamental do ser quando no enfrentamento de determinadas situações fáticas que lhe possam exigir tomadas de decisões importantes; e as ações cotidianas, inspiradas pela vivência sociocultural relativa ao contexto em que o indivíduo está inserido, a exemplo de suas crenças, seus costumes, seus hábitos e suas tradições.

A respeito deste contexto sociocultural, Simonassi e Machado. ${ }^{11}$ conduziram vários experimentos que demonstraram como o contexto altera os relatos verbais. Daí entendermos a relatividade implicada na prova 
testemunhal e da qual deverá surgir uma sentença absolutória ou condenatória de determinada pessoa num processo de natureza penal/criminal, onde as sanções poderão impor a perda de um dos mais preciosos bens do ser humano: a sua liberdade.

\section{Acerca do comportamento verbal}

Skinner ${ }^{3}$, acerca da definição de comportamento verbal, nos diz que

Uma concepção muito mais produtiva é a de que comportamento verbal é comportamento. Tem caráter especial tão-só porque é reforçado por seus efeitos sobre as pessoas - de início, outras pessoas, mas eventualmente o próprio falante. Por conseguinte, está isento das relações espaciais, temporais e mecânicas que prevalecem entre o comportamento operante e as consequências não-sociais (p.79).

O comportamento verbal tem sido alvo de constantes estudos, principalmente a partir do Behaviorismo Radical proposto por Skinner ${ }^{3}$. Diretamente do interesse deste artigo nos valeremos em nossa pesquisa dos conhecimentos ensinados por Todorov ${ }^{12}$, o qual buscou entendimento acerca da definição do termo "comportamento".

Por meio da leitura deste autor, alcançamos a compreensão de que definições por si só também carecem de definições que acabam por gerar entendimentos que dependem de novas explicações e que, desta forma, o que se pode alcançar nada mais é do que uma aproximação menos obscura do que um determinado termo queira significar. $^{12}$

\section{Da definição de comportamento e de sua classificação}

Em seu artigo "Sobre uma definição de comportamento", Todorov ${ }^{12}$ apresenta e questiona a visão mais corrente de comportamento como sendo "interações de qualquer organismo com seu meio ambiente" e que tais relacionamentos são "interações que envolvem alguma alteração no organismo com alguma alteração no ambiente". Sobre tal informação, acabamos por observar que tal conceito estaria mais bem expresso se o termo "organismo" fosse substituído por "pessoa", uma vez que quem se comporta é a pessoa. Vejamos tal posição, segundo a ótica de Skinner ${ }^{3}$ :

Uma pessoa não é um agente iniciador; ele é um lócus, um ponto em que múltiplas condições genéticas e ambientais se reúnem num efeito conjunto. Enquanto tal, ela permanece indiscutivelmente única. Ninguém mais (a menos que ela tenha um gêmeo idêntico) tem sua dotação genética e, sem exceção, ninguém mais tem a sua história pessoal (p.168).

Depreendemos, desta forma, que o organismo seria tão somente parte do sujeito e que se assim o considerássemos estaríamos desprezando sua essência, sua história e todos os repertórios por ele adquiridos e que teriam relevância na expressão de seus comportamentos. E, como exposto, da interação desta pessoa com o meio, resultando em repercussões consequenciais, seria alcançado o sentido do comportar-se. Não percamos de vista que a pessoa é parte do ambiente em que se comporta.

Todorov $^{12}$ faz críticas pertinentes ao conceito do termo "comportamento", alcançando o entendimento de que comportamento não é a "interação entre organismo e ambiente", uma vez que "a contingência não é o comportamento" em si (p.34). Assim, entendemos que comportar-se é, numa compreensão ainda parca, toda ação ou conjunto de ações em resposta a estímulos externos e/ou internos com expressão pública e/ou privada e que decorre da interação do ser com o meio - do qual também é parte -, podendo tal expressão ser inata ou adquirida.

De acordo com Moreira ${ }^{13}$ comportamento respondente é um tipo de comportamento em que uma alteração no ambiente seria capaz de eliciar uma resposta, ao passo em que comportamento operante seria uma nova resposta emitida pelo sujeito com a geração de uma alteração consequencial no ambiente. Porém, há que se observar que o comportamento verbal, como comportamento operante que é, dependeria não só de controles a partir das consequências que poderão advir dele como também é possível que seja emitido sob o controle de estímulos antecedentes.

Ainda segundo Moreira ${ }^{13}$ o comportamento seria, quando operante, aquele que fosse afetado - controlado - por suas consequências, as quais influenciariam ocorrências futuras, em maior ou menor frequência. Tais consequências seriam reforçadores, positivos ou negativos, capazes de controlar a maior ou menor ocorrência dos mesmos fatos que lhes deram origem.

Dentre tais ações anteriormente classificadas como sendo comportamentais, temos, portanto, o comportamento verbal, o qual é compreendido como sendo um comportamento operante e relevantemente relacionado às suas consequências ou dependente de estímulos antecedentes. E sobre este ponto, oportunamente, focaremos nossas análises acerca do valor da prova testemunhal no âmbito jurídico penal/ criminal.

Portanto, voltando às nossas análises acerca do comportamento verbal, temos que os estímulos antecedentes são parte do controle de nossas respostas e tais respostas ocasionam consequências e que tais consequências modificarão a frequência desta classe de operantes. Segundo Moreira ${ }^{13}$ : “os estímulos que 
sinalizam que uma dada resposta será reforçada são chamados de estímulos discriminativos [...]” (p.99). Desta forma, compreendemos que quando temos interesse em algum resultado e tal resultado é ou pode ser alcançado por nosso comportamento verbal - mentindo, por exemplo -, tal resultado obtido agirá como reforçador de nossa ação subsequente.

E, em relação ao objeto de nossa pesquisa - o valor da prova testemunhal no âmbito jurídico penal/ criminal -, todas as contingências deverão estar sob a luz de análises para que se possa compreender seus papéis, suas importâncias e as implicações que delas resultam. Nesse sentido, apesar de sabermos que o comportamento verbal não se restringe à oralidade exigida na emissão de testemunhos, não poderemos considerar o papel do comportamento verbal não vocal nestas situações, tendo em vista que as expressões corporais emissoras de mensagens não são passíveis de serem mensuradas de forma confiável para que se possa garantir que um gesto tal ou qual - esfregar as mãos, suar, gaguejar, ter as mãos frias etc. - certifique inequivocamente que uma determinada testemunha mentiu em suas declarações.

A correspondência implícita no comportamento operante (se... então) é contemplada em nosso ordenamento jurídico naquilo que diz respeito à prova testemunhal no foro penal. Vejamos o exposto em nosso CPP: “Art. 210. As testemunhas serão inquiridas cada uma per si, de modo que umas não saibam nem ouçam os depoimentos das outras, devendo o juiz adverti-las das penas cominadas ao falso testemunho" ${ }^{2}$.

Ou seja, se emitirem falso testemunho, então serão penalizadas. Portanto, entendemos tal contingenciamento apontado no supracitado artigo do CPP como sendo uma clara forma de controle aversivo. Também sobre isto versou Moreira ${ }^{13}$ :

O controle aversivo, de acordo com o que vimos, é uma forma legítima e eficiente de aumentar ou de diminuir a probabilidade de emissão de comportamento. Punir comportamentos inadequados ou indesejados é muito mais fácil e tem efeitos mais imediatos do que reforçar positivamente comportamentos adequados (p.75).

\section{Do episódio verbal e a correspondência entre fazer/dizer e dizer/fazer}

Segundo Wechsler ${ }^{10}$ : "correspondência verbal pode ser definida como a relação entre o comportamento verbal e o não-verbal de um indivíduo" (p.189). Assim, é de se entender que a relação entre o dizer e o fazer, e vice-versa, seja útil na análise das provas testemunhais e/ou decorrentes de depoimentos prestados à Justiça, quando da busca de uma "verdade dos fatos". Ou seja, espera-se que entre o que se diz e o que se faz ou entre o que se faz e o que se diz possa ser possível a existência de algo observável, mensurável e que venha a servir como parâmetro observacional a partir de tal correlação.

Amorim, citado por Simonassi e Machado ${ }^{11} \mathrm{em}$ experimento por eles elaborado e publicado, nos informa que, como pesquisador,

[...] verificou que a ocorrência de correspondência é mais provável quando há uma história de reforçamento para a correspondência, pois reforçar um componente da resposta (verbal ou não verbal) não foi suficiente para manter a outra. Assim, correspondência parece caber bem no conceito de operante complexo pelo qual componentes múltiplos podem ocorrer por reforçamento (p.36).

E desta mencionada complexidade deverão surgir dúvidas bastante significativas no âmbito jurídico, tendo em conta a visão geralmente positivista nele adotada. Para melhor entendermos isto, deveremos recorrer, antes de tudo, aos conceitos de comportamento verbal, episódio verbal, mando e tato verbal.

De acordo com Alves ${ }^{14}$, acerca do comportamento verbal e como já visto anteriormente, de acordo com Skinner ${ }^{3}$ temos que

[...] é o operante verbal que faz contato com o mundo, ou seja, pode descrevê-lo. É possível emitir tatos de estímulos físicos, de acontecimentos sociais, de eventos privados, e até mesmo de outros tatos. Seu controle ocorre por estímulos antecedentes não-verbais e seu reforço se caracteriza por ser generalizado. Assim, utilizando a contingência de três termos para analisálo, podemos afirmar que a relação entre o estímulo antecedente e a resposta é específica, mas a relação entre a resposta e o evento reforçador é generalizada. Por exemplo, na presença de um cachorro, o falante pode emitir a resposta verbal "Isto é um cachorro" e receber reforçadores generalizados como a atenção e/ ou verbais, "isto mesmo, você está certo". (s/n)

Com relação ao mando, Alves $^{14}$ nos informa que

O mando está sob controle antecedente de estados motivacionais e seu reforço é específico em relação à resposta. Para Skinner (1953/2000), um estado motivacional se refere simplesmente às operações de privação, saciação e estimulação aversiva. Esse operante verbal permite ao falante a emissão de uma resposta que especifique o estímulo reforçador para a solução do estado motivacional. Por exemplo, um falante sedento pode pedir água a um ouvinte e seu comportamento ser reforçado ao receber a água. ( $\mathrm{s} / \mathrm{n})$

De acordo com Juliani ${ }^{8}$,

$\mathrm{Na}$ definição de comportamento verbal proposta por Skinner ${ }^{3}$, a análise do mando recai sobre o comportamento do falante, porém não é descartada a importância de um ouvinte para que se constitua o que 
ele chamou de episódio verbal. Um episódio verbal é definido como trocas entre falante e ouvinte de tal forma que o comportamento de um afete o comportamento do outro (p.18).

Desta forma, o comportamento do falante - no caso jurídico, a testemunha - é facilmente influenciado por variáveis relacionadas à audiência, conforme demonstraram Simonassi e Machado. ${ }^{11}$ Quando temos a interação observável entre falante e ouvinte, dizemos que se estabeleceu um episódio verbal - mesmo que o ouvinte seja, no mesmo episódio, o falante. Este falante emite mandos que podem ser ou não respondidos pelo ouvinte e este ouvinte libera reforçadores para o comportamento do falante.

O grande problema é saber sob o controle de quais variáveis o falante se achará no momento em que se configurar como uma testemunha ou um depoente num processo penal/criminal. Eventos consequentes ou estímulos antecedentes poderão funcionar como controladores do comportamento verbal do falante na condição de testemunha ou de depoente no plano jurídico envolvendo o julgamento de um fato delituoso.

Voltando a Wechsler ${ }^{10}$ : "para De Rose (1999) e Sadi (2002), a correspondência verbal seria um exemplo de controle de estímulos, em que um estímulo discriminativo controlaria um tato verbal" (p.190). E, neste sentido, a mesma autora informa que "a correspondência pode ser um fenômeno social", uma vez que "a mentira ou a falsa promessa" funcionaria como algo aversivo para o que ouve e que, por consequência, isto afetaria comportamentos de correspondência emitidos posteriormente pelo falante. ${ }^{10}$

Citando Catania, Wechsler ${ }^{10}$ (p.190) nos dá a entender que aquilo que denominamos de "verdade" está sob o controle da forma como a comunidade verbal mantém as correspondências entre o comportamento verbal e o ambiente.

Portanto, depreendemos de todo o exposto e por analogia que as contingências do momento testemunhal poderão afetar a relação entre o que tiver sido observado ou vivenciado e o que será relatado, sobretudo levandose em conta as implicações advindas de tais relatos. Por implicações devemos entender as consequências dos comportamentos. Neste rol de possíveis implicações jurídicas podemos ter as punições, por exemplo. Assim, entendemos que a correspondência entre fazer-dizer - no caso em estudo, entre o observar ou vivenciar e o relatar - estará sujeita a uma enormidade de variáveis controladoras capazes de afetar de forma relevante o comportamento verbal vocal de uma testemunha ou de um depoente.

Sabe-se, por estudos experimentais, que a correspondência perfeita entre o fazer e o dizer ou o dizer e o fazer só ocorrem sob condições muito especiais. De forma genérica, a correspondência fazer/dizer e dizer/ fazer é apenas parcial ${ }^{11}$. Mais adiante voltaremos neste ponto.

\section{Acerca da mentira como forma de comportar-}

se

Após lançadas estas descrições anteriormente postas, devemos voltar nossa atenção para o comportamento verbal vocal daquele que mente, uma vez que é dessa possibilidade que ocorre a falta de credibilidade na prova testemunhal ao ponto de condenála a se configurar como sendo a "prostituta das provas". Em relação a tal situação, temos que:

“'As aventuras de Pinóquio' é uma história clássica
da literatura infantil, cujo personagem principal é
um boneco de madeira que quer ser um 'menino de
verdade'. Uma das grandes lições dessa história envolve
o tema mentira. O boneco mente e, com isso, se envolve
em muitos problemas. Para ser merecedor da condição
humana, entre outras coisas, ele não deve mentir. Dessa
forma, é possível verificar alguns valores culturais
sobre a mentira: 'meninos bons não mentem', 'aquele
que mente, não vai ter sucesso e sim um castigo ${ }^{15}(p .1)$.

Novamente nos deparamos com a função do controle aversivo imposto social, cultural e politicamente sobre o comportamento de mentir. Porém, havemos de refletir sobre o tema questionando-nos o valor da mentira em relação ao contexto em que a mesma possa ser emitida. Suponhamos que um jovem entre em casa dizendo-se perseguido por alguém que intenta matá-lo. Após ter dito isto ao pai, o jovem se esconde sob uma cama e, na sequência, tal agressor adentra a casa com um revólver em punho e pergunta sobre o paradeiro daquele a quem procura. Que atitude correta deve ser tomada pelo pai do jovem: mentir e salvar-lhe a vida ou dizer a verdade e permitir-lhe ser morto?

No entanto, em casos envolvendo a necessidade de promoção da justiça, a mentira pode influenciar de maneira decisiva na emissão de uma sentença desfavorável a um inocente que esteja sendo caluniosamente acusado. Isto poderá repercutir em sua vida pessoal com a perda de sua liberdade e, em se tratando de estupro, por exemplo, até mesmo em sua integridade física, uma vez que detentos não toleram estupradores em meio a eles.

Seria, pois, necessária a busca de mecanismos que pudessem apontar os falsos testemunhos e que, assim, caíssem por terra os interesses escusos de caluniadores. Refletindo sobre tal possibilidade, tentamos buscar na correspondência entre comportamentos verbais e não verbais ou na consistência entre duas ou mais fontes de verbais vocais e relacionadas a não verbais uma ferramenta capaz de permitir que se observem incongruências e discrepâncias capazes de nos municiar com um arsenal 
avaliativo confiável e com menor probabilidade de erros quando de sua verificação científica ${ }^{16}$.

Tal correspondência ocorreria entre o comportamento verbal - vocal - e o não verbal ou até mesmo o verbal não vocal. Porém, que grau de confiabilidade poderia ser creditado neste sentido? E esta acaba por ser a pergunta-chave norteadora desta pesquisa. Os operadores do Direito disporão de outros mecanismos para que se possa alcançar a confiança num depoimento prestado e um deles seria, por exemplo, a apresentação de um álibi inquestionável. Mas, nem sempre isto será possível e tudo ficará no plano do comportamento verbal vocal. Seria a palavra de um contra a palavra de outro num embate de interesses e de infindável ocorrência.

Wechsler ${ }^{10}$, em seu artigo "Correspondência verbal: uma revisão da literatura" cita que:

Correspondência verbal é comumente definida na literatura como a relação entre o comportamento verbal e o não-verbal de um indivíduo [...] entendendo-se como comportamento verbal um operante com uma característica singular: a mediação realizada por outra pessoa [...] (p.190).

Mais adiante, ainda no mesmo $\operatorname{artigo~}^{10}$, e citando Catania, a autora complementa que

A comunidade verbal mantém a correspondência entre o comportamento verbal e os eventos ambientais porque somente quando o comportamento do falante for consistente é que ele fornece estímulos discriminativos para gerar um comportamento no ouvinte. Ao longo da vida do indivíduo, a comunidade testa intermitentemente a fidedignidade de um relato sobre um evento. O que chamamos de verdade depende de como a comunidade verbal mantém as correspondências entre o comportamento verbal e o ambiente (p.190).

Ou seja, a mentira poderia ser considerada como sendo a não correspondência entre os comportamentos verbal e não verbal e até mesmo entre o verbal não vocal e o verbal vocal. E, ainda mais, acrescentamos uma não correspondência entre o declarado e o verificado, incluindo-se aí não só a mencionada relação de veracidade entre o dizer e o fazer, como também a discrepância com os fatos capazes de serem observados e comparados com outros fatos. Como exemplo, poderíamos citar uma pessoa dizendo que não se achava no local de um crime quando câmeras de vigilância gravaram sua presença no local e hora dos fatos.

Os falsos testemunhos estariam, portanto, na dependência dos fatores contingenciais diretivos dos diversos interesses envolvidos numa lide. O grande problema reside na comprovação das inverdades emitidas pela testemunha ou, até mesmo, numa verdade contaminada por variáveis diversas e não correspondendo ao que de fato teria ocorrido. Assim, devemos também entender que nem toda mentira teria a finalidade de enganar, embora os prejuízos decorrentes disso também pudessem se fazer valer de maneira catastrófica.

Nietzsche ${ }^{17}$, em sua obra "Sobre verdade e mentira no sentido extra-moral", nos leva a entender, que

Movida pela crença de que a forma fundamental do pensamento é a mesma de suas manifestações por palavras, desde cedo, a filosofia não hesitou em identificar discurso e realidade. Concebendo o pensar como uma inequívoca atividade de simbolização enunciativa, ela parece ter sempre dado atenção especial à dimensão apofântica da linguagem, tomando enunciados verbais por verdadeiros ou falsos, em função de descreverem corretamente ou não o mundo. $\mathrm{O}$ que ocorreria, porém, se a verdade dos enunciados não passasse de um tipo de engano sem o qual o homem não conseguiria sobreviver? E se a condição da verdade fosse a mesma da mentira? Revelar-se-ia, então, o atávico caráter dissimulador do intelecto humano e, com ele, a suspeita de que entre o "refletir" e o "dizer" não vigora nenhuma identidade estrutural (p.10).

É de se questionar também o papel hereditário genético-do mentir como mecanismo de defesa adquirido pelo homem ao longo de sua história. No entanto, nem sequer podemos aceitar inequivocamente a existência do mentir como mecanismo de defesa geneticamente herdado e pertencente a uma classe de caractere adquirido por meio da evolução da espécie. Mas, para além desta discussão, o que devemos entender, levando-se em conta o foco desta pesquisa, não é o "por que mentimos?", e sim as consequências do mentir relativas a processos judiciais penais/criminais e, principalmente, se é possível a elaboração de um conjunto de instrumentos avaliativos periciais competentes para a busca das provas relativas aos falsos testemunhos.

Neste sentido, a pesquisa deverá apontar para a análise da correspondência entre os comportamentos verbal e não verbal, e/ou verbal/verbal, bi-comparado ao não verbal, com a intenção direta de acessar as variáveis capazes de subsidiar a afirmação de que uma testemunha estaria mentindo quando dos seus relatos acerca de um fato criminalmente questionado e do qual poderia resultar injusta condenação ou absolvição do acusado. Segundo podemos depreender da leitura de Vrij ${ }^{18}$ os aspectos referentes ao plano emocional, à complexidade cognitiva e às tentativas de controle de comportamento são relevantes para a previsão e explicação do comportamento não-verbal implicando em um ato de mentir. A pesquisa realizada acabou por revelar a inexistência de um comportamento tipicamente enganoso. No entanto, também se alcançou o entendimento de que alguns comportamentos são mais comuns durante o ato de enganar e que estes são mais dependentes das emoções experimentadas pelo mentiroso, do entendimento experimentado pelo mentiroso, assim 
como a quantidade de esforços empreendidos no controle de seu comportamento.

Assim, compreendemos que não é possível o alcance de um padrão típico de comportamento enganoso e que variáveis independentes exercem relevante papel na manutenção e ou emissão da mentira como comportamento. Do mesmo trabalho - e igualmente por meio de leitura interpretativa analiticocrítica entendemos, complementarmente, que tais variáveis podem agir simultaneamente e que determinados sinais - demonstração de nervosismo, esforços de pensamento para lembrar-se de fatos, tentar controlar-se ao mesmo tempo em que se emite um relato - podem ser observados. Espera-se que os mentirosos se demonstrarão mais nervosos quando as consequências negativas e positivas envolvidas forem elevadas e, desta forma, comportamentos nervosos são mais prováveis de ocorrer em altas apostas referentes a uma mentira. Mentiras mais complexas implicariam ainda em um maior esforço de pensamento para sua elaboração e a carga cognitiva seria, portanto, mais amplamente exigida nesses casos ${ }^{18}$.

$\operatorname{Vrij}^{18}$, citando outro de seus trabalhos, aponta ainda para o fato de que os bons mentirosos são aqueles capazes de administrar os sinais de nervosismo e de esforços cognitivos, principalmente em circunstâncias mais difíceis, no sentido de tentar ocultar comportamentos que possam parecer anormais e impor aos seus comportamentos uma aparência de normalidade para os observadores. Tentam parecer, dessa forma, o mais honestos quanto forem capazes.

Ao finalizar suas pesquisas através de um método combinado de análise de comportamentos verbais e não verbais com crianças e adultos, Vrij acabou por concluir que tal técnica se demonstrou interessante, mas que conclusões precisas não puderam, no entanto, ser alcançadas no atual estágio, mas que os resultados, porém, são promissores. Entretanto, finalizou seu trabalho indicando que seria importante a verificação de se julgamentos precipitados acerca de sinais relevantes não provocariam um aumento na detecção de mentiras, ou seja, segundo pudemos compreender, se não estaríamos superestimando tais sinais e elevando artificialmente os níveis de detecção de mentiras inexistentes ${ }^{18}$.

\section{DA IMPORTÂNCIA DO COMPORTAMEN- TO VERBAL E DA EMISSÃO DE MENTIRAS NOS TESTEMUNHOS CRIMINAIS}

Tendo-se como base o que expusemos anteriormente, sabemos que a prova testemunhal depende exclusivamente da emissão de um comportamento verbal - neste caso específico, vocal - que nada mais seria do que um comportamento operante, tendo em vista as consequências que ele é capaz de gerar no ambiente, especialmente no ouvinte ${ }^{13}$. E, em sendo um comportamento operante, estará tal prova sujeita às influências de inúmeras variáveis, verbais e/ou não verbais.

Interesses diversos estarão implicados na emissão de determinados relatos pertinentes a um específico fato sob investigação criminal e que as contingências envolvidas se somarão a este cenário, podendo disto resultar a necessidade da emissão de mentiras como forma de beneficiamento de uma ou outra parte envolvida numa lide judicial penal/criminal.

Importante, então, se faz a observação da veracidade ou não dos relatos testemunhais para que o julgamento não se torne contaminado por artifícios capazes de desviar a sentença para qualquer dos lados, mas especialmente para aquele não detentor da verdade dos fatos, o que culminaria com uma injusta condenação de um inocente e uma absolvição de um culpado.

Como se trata de um comportamento verbal vocal, a testemunha, apesar de se achar sob juramento, poderia emitir uma versão completamente falsa caso fosse treinada para tal ato, sobretudo se fosse desprovida de valores morais mais consolidados ou se os danos decorrentes de sua fala fossem muito expressivos para alguém de seu relacionamento ou até se os seus interesses fossem direcionados para a punição de outrem, mesmo que este outro fosse, sabidamente de sua parte, inocente.

As consequências das variáveis controladoras das respostas específicas de um contexto de uma testemunha teriam, pois, importante valor reforçador. Mas, desejar mentir não implica em saber mentir, uma vez que contradições acabariam por surgir, demandando novas mentiras que, por sua vez, seriam insustentáveis quando confrontadas com outros fatos, especialmente aqueles capazes de serem comprovados por meio de algo observável, a exemplo de uma folha de ponto, um registro por meio de câmera de vigilância, do rastreamento de um aparelho celular por uma Estação Radiobase - ERB - etc.

Porém, nem toda mentira, do ponto de vista testemunhal, poderá contar com tal confrontamento de dados, como é o caso de uma pessoa que tem todas as provas de que manteve relação sexual com alguém e que alega não ter consentido para o ato quando o outro envolvido na relação afirma que obteve tal consentimento. Estaríamos, assim, diante de uma situação em que seria "palavra contra palavra" dificultando a análise judicial do fato.

O conhecimento das consequências relativas ao falso testemunho - elencadas pelo julgador durante o compromisso de não mentir, sob pena de responder por crime de perjúrio - nem sempre é capaz de afastar a necessidade da emissão de uma inverdade, tendo em vista que outras variáveis poderiam representar maiores perdas para a testemunha ou para alguém de seu interesse, vindo assim a controlar o seu comportamento verbal vocal.

O mentir, como pudemos analisar na leitura de 
Vrij ${ }^{18}$, envolve reações orgânicas e cognitivas capazes de serem observadas, desde que sejam desenvolvidos instrumentos ou técnicas para tal. Porém, o próprio estresse de se achar na frente de um juiz, num Tribunal do Júri, igualmente poderia gerar tais respostas sem que se estivesse mentindo. Determinados comportamentos verbais/não verbais seriam atitudes possíveis mesmo quando se estivesse emitindo um conjunto de respostas verdadeiras. Ou seja, tais reações não podem nem devem ser adotadas como sinais inequívocos de que uma testemunha está a mentir ${ }^{17}$.

O comportamento verbal - vocal no caso de testemunhas -, por ser operante, estaria também controlado pelos ouvintes do falante e, assim sendo, a simples visualização de uma pessoa com atitudes coercitivas na assistência - o próprio réu, familiares da vítima ou do réu etc. - seria fator suficiente para que a emissão do comportamento verbal vocal fosse reforçada de forma negativa ou positiva.

Segundo Moreira e Medeiros ${ }^{13}$ : "no momento em que os organismos entram em contato com estímulos aversivos, é observada a eliciação de várias respostas emocionais, como tremores, taquicardia, palpitações, choro, etc.”. E tal afirmação nos permite compreender que as testemunhas em casos envolvendo fatos criminais acabarão por se achar diante de estímulos que lhes serão aversivos e suficientemente capazes de alterar-lhes a expressão emocional com repercussão sobre a fisiologia corporal.

E tal situação de enfrentamento de uma exposição diante de uma audiência judicial ou até um tribunal do júri, mesmo para aqueles que não tenham relação com os fatos, mas que somente os presenciaram, funcionaria como algo temeroso e constrangedor, sobretudo quando do seu comportamento verbal vocal dependesse a condenação ou absolvição de alguém.

Portanto, parece-nos claro que o comportamento verbal vocal de uma testemunha estará diretamente ligado a estímulos externos e/ou internos - de foro íntimo - capazes de interferir, senão na veracidade dos fatos, na forma como serão expressados e interpretados por quem de fato julga o caso criminal em foco num determinado momento. Assim, o comportamento verbal vocal do falante - quando testemunha - refletirá sobre seu comportamento não verbal e verbal não vocal, tendendo a influenciar a compreensão, pelos ouvintes, dos fatos narrados numa situação de audiência ou de tribunal de júri. E disto poderá resultar maior ou menor confiabilidade naquilo que tiver sido exposto.

Isto justifica porque se considerar a prova testemunhal como sendo a "prostituta das provas", dada a sua fragilidade diante de estímulos reforçadores tanto do falseamento da verdade quanto da expressão inadequada do comportamento humano - verbal e/ou não verbal - diante de situações críticas, como aquelas representadas pela exposição pública em casos de julgamentos criminais.

\section{CONCLUSÃO}

Segundo pudemos compreender das pesquisas literárias por nós realizadas - destacando-se Skinner ${ }^{3}$ - e tomando-se por base que a prova testemunhal é um comportamento verbal vocal e que como todo comportamento verbal é um comportamento operante, ela acabará por influenciar o meio ambiente representado pela plateia de ouvintes numa audiência ou num tribunal do júri, além de atuar sobre o próprio falante que é ouvinte de si mesmo.

Estímulos externos - presença de algum criminoso sob julgamento, de familiares da vítima, do próprio juiz, do promotor, da imprensa etc. - e internos - questões de foro íntimo, pertenças religiosas, conflitos morais etc. - são capazes de adicionar comportamentos não verbais e/ou verbais não vocais à fala de uma testemunha, gerando maior ou menor credibilidade do que a normalmente esperada de acordo com os fatos narrados.

Gaguejar, transpirar profusamente, titubear nas respostas, esfriar as mãos, balançar continuadamente as pernas etc., podem ser comportamentos confundidos como resultantes da emissão de mentiras. Treinamentos prévios podem gerar atitudes de frieza capazes de impor aspecto de veracidade a fatos narrados e não verídicos. As próprias penas previstas em lei e advertidas pelo juiz antes da emissão do testemunho funcionariam como mecanismos controladores aversivos importantes.

Percebe-se, portanto, pelo conjunto de fatos apresentados, que a questão testemunhal é bastante complexa e que envolve comportamentos - verbais e/ ou não verbais - importantes e capazes de representar interpretações diversas por parte dos ouvintes, podendo conferir-lhe valores contrários aos que na verdade representam e justificando, desta forma, sua pobreza probatória no âmbito do foro penal/criminal.

Assim, podemos notar que a prova testemunhal é um comportamento verbal vocal sujeito à influência de diversas variáveis que, por sua vez, não são facilmente identificáveis. A prova testemunhal estaria, portanto, sob o controle de variáveis desconhecidas, a exemplo de interesses financeiros, patrimoniais, relacionamentos etc. e que escapam ao controle da Justiça e dos operadores do Direito. Por isto, só deverá apresentar valor de prova quando outros elementos a ela se juntarem, como seria o caso de contradições e/ou de provas materiais concretas contrárias ou favoráveis aos relatos emitidos pelas testemunhas. 
Cardoso LM, Simonassi LE. A medical expert view on the witness evidence of the value in the criminal/legal framework. Saúde, Ética \& Justiça. 2015;20(2):66-76.

\begin{abstract}
This article deals with the issues regarding the value of oral testimony focusing on the analysis of verbal behavior corresponding to the verbal and nonverbal behavior, seeking elements that might or might not be sufficiently valid according to the criminal/legal criteria. The objective of the research is to seek if there are such elements and if their probative value would have weight from a practical point of view in hearings and jury trials, since the medical and forensic evidence does not always adequately fill this need. The aforementioned juridical subsidies would tend to minimize any mistakes that might be made in these areas of Justice, which as such reflects the relevance of the subject. To address this, we undertook a qualitative analysis, based on literary, dissertative, descriptive and exploratory research. Our main theoretical references were the Criminal Procedure $\mathrm{Code}^{2}$ and, for the authorial reference base, Skinner ${ }^{3}$. We finally arrived at the conclusion that, because it is verbal behavior subject to the influence of several variables, which are not identifiable and whose controllers are not easily noticeable, the testimonial evidence has no concrete basis that could be considered reliable, except when other variables - such as contradictions and/or concrete physical evidence - are found.
\end{abstract}

KEY WORDS: Expert testimony; Verbal behavior; Criminal law, Criminology.

\title{
REFERÊNCIAS
}

1. Calaes C, Zuba F. STJ dará a palavra final sobre um dos maiores erros jurídicos em MG. Hoje em Dia. 2013 [Acesso em 09 jun 2015]. Disponível em: http://hojeemdia.com.br/ horizontes/stj-dar\%C3\%A1-a-palavra-final-sobre-um-dosmaiores-erros-jur\%C3\%ADdicos-em-mg-1.144332.

2. Brasil. Presidência da República, Casa Civil, Subchefia para Assuntos Jurídicos. Código de Processo Penal. Rio de Janeiro, RJ; 1941. Disponível em www.planalto.gov.br/ ccivil_03/decreto-lei/del3689.htm

3. Skinner BF. O comportamento verbal. São Paulo: Cultrix; 1957.

4. Santos DCB. A credibilidade da prova testemunhal no processo penal [Monografia]. Curitiba: Fundação Escola do Ministério Público do Paraná - FEMPAR, Faculdades Integradas do Brasil - UniBrasil; 2010.

5. Brasil. Presidência da República, Casa Civil, Subchefia para Assuntos Jurídicos. Constituição da República Federativa do Brasil de 1988. Brasília, DF; 1988. Disponível em: http://www.planalto.gov.br/ccivil_03/constituicao/ ConstituicaoCompilado.htm.

6. Campina ACC. António de Oliveira Salazar: discurso político e "retórica" dos direitos humanos. Salamanca (Espanha): Ediciones Universidad Salamanca; 2013. Disponível em: https://goo.gl/y8NntI.

7. Borloti E, Iglesias A, Dalvi CM, Silva RDM. Análise comportamental do discurso: fundamentos e método. Psicol Teorias Pesq. 2008;28(1):101-10. Disponível em: http:// www.scielo.br/pdf/ptp/v24n1/a12v24n1.pdf.

8. Juliani J, Garcia MR, Athayde Neto CA, Massabki LGS, Arndt MFC. Episódios verbais como instrumento para a análise da relação terapêutica. Rev Bras Ter Comportamental Cogn. 2011;13(3):16-33. Disponível em: http://pepsic. bvsalud.org/pdf/rbtcc/v13n3/v13n3a03.pdf.

9. Bottomore $\mathrm{T}$, Nisbet R, organizadores. História da análise sociológica. Rio de Janeiro: Zahar; 1980.

10. Weschler AM, Amaral VLR. Correspondência verbal: uma revisão da literatura. Rev Bras Ter Comportamental Cogn. 2009;11(2):189-208. Disponível em: http://www.usp.br/ rbtcc/index.php/RBTCC/article/view/398.

11. Machado DJC, Simonassi L. O comportamento verbal: análise das interações falantes e ouvintes. Saarbrücken (Alemanha): Novas Edições Acadêmicas; 2014.

12. Todorov JC. Sobre uma definição de comportamento. Perspectivas. 2012;3(1):32-7.

13. Moreira MB, Medeiros CA. Princípios básicos de análise do comportamento. Porto Alegre: Artmed; 2007.

14. Alves C, Ribeiro AF. Relações entre tatos e mandos durante a aquisição. Rev Bras Ter Comportamental Cogn. 2007;9(2):289-305. Disponível em: http://pepsic. bvsalud.org/pdf/rbtcc/v9n2/v9n2a11.pdf.

15. Fonseca FN. "Eu sou o cara": análise comportamental do relato de um mentiroso [monografia]. Brasília: Instituto Brasiliense de Análise do Comportamento; 2012.

16. Leme VBR, Bolsoni-Silva AT, Carrara K. Uma análise comportamentalista de relatos verbais e práticas educativas parentais: alcance e limites. Paideia (Ribeirão Preto). 2009;19(43):239-47. DOI: http://dx.doi.org/10.1590/S0103863X2009000200012.

17. Nietzsche WF. Sobre verdade e mentira. São Paulo: Hedra; 2007.

18. Vrij A, Akehurst L, Soukara S, Bull R. Detecting deceit via analyses of verbal and nonverbal behavior in children and adults. Hum Commun Res. 2004;30(1):8-41. DOI: http:// dx.doi.org/10.1111/j.1468-2958.2004.tb00723.x. 